\title{
Application of hourly dynamic method for nZEB buildings in Italian context: analysis and comparisons in national calculation procedure framework
}

\author{
Domenico Palladino ${ }^{1,}$, Domenico Iatauro ${ }^{1}$ and Paolo Signoretti ${ }^{1}$ \\ ${ }^{1}$ Italian National Agency for New Technologies, Energy and Sustainable Economic Development \\ (ENEA), DUEE Department, 00123 via Anguillarese 301 Santa Maria di Galeria (Rome), Italy
}

\begin{abstract}
The Energy Performance of Buildings Directive (EPBD 2018/844/EU) requires to Member States to upgrade the methodology for the energy performance assessment of buildings. The current calculation method, based on the monthly quasi steady state calculation procedure, could be replaced in the next years by an hourly dynamic calculation procedure (EN ISO 52016), in which a resistance-capacity (RC) model is implemented to consider with more accuracy the heat exchange through the building envelope. In this framework, the present work aims at analysing and comparing the energy needs of three reference case studies of nearly Zero Energy Buildings (nZEB), applying both calculation procedures in order to investigate the main difference of the two approaches. Two residential buildings and one office, compliant with Italian minimum requirements for nZEB, were defined, and several energy simulations were carried out for all different climatic zones of Italian territory. Preliminary results highlighted significant differences of energy need mainly due to different weight of heat loss and heat gains obtained with the two considered calculation methods. This paper represents a preliminary study, but further analysis are recommended in order to evaluate the overall energy use for different type and different operation profile of buildings.
\end{abstract}

\section{Introduction}

The European Energy Performance of Buildings Directive 2010/31/EU (EPBD) [1] has established a legislative framework aimed to increase the energy performance of buildings. According to [1] for all the Member States is mandatory to assess the cost-optimal levels of minimum energy performance requirements. Moreover, in Italy, since $31^{\text {st }}$ December 2020, all new buildings have to be nearly Zero Energy Buildings (nZEB).

The Decree 26 June 2015 [2] provides the methodologies for the energy performance calculation, the prescriptions, and minimum requirements for buildings. Currently, according to the new energy requirements, each building have to be compared with a "reference

\footnotetext{
* Corresponding author: domenico.palladino@enea.it
} 
building" which is a building with the same geometry, location, and use, but having specific efficiency standards for building envelope and energy system defined by the law [2].

The calculation method to be applied for the global primary energy evaluation which includes the space heating, cooling, domestic hot water production (DHW), ventilation, lighting and internal transports, is provided by the technical specifications UNI/TS 11300 $[3,4]$, based on the quasi-steady-state method on a monthly basis given by UNI EN ISO 13790 [5].

In 2018, a new EPBD (European Directive 2018/844/EU [6]), required to Member States to match the calculation methodology for the energy performance of buildings according to specific general standards including ISO 52016-1 [7]. The UNI EN ISO 52016-1 is currently out of the legal context provided by Decrees [2].

In this legislative framework, it is important to investigate how could and should be changed the minimum requirements especially for the new construction which should be compliant with nZEB requirements.

The methodology for the energy assessment of buildings is one of the most important topic that has been studied in the Literature; since ISO 52016-1 is recently issued, the energy analysis with this methodology is only at beginning. Some studies were carried out in 2020 mainly focused on this new approach and on its impact in terms of calculation accuracy for specific case study [8-13]. For instance, Zakula et al. [9] carried out a comparison analysis between ISO 52016 and dynamic simulations, highlighting important differences in terms of heat transfer through the windows and annual energy need for heating and cooling. Also Ballarini et al [11] compared results of EN 52016 with dynamics simulations in order to check its validity. In this case, the main differences obtained for the investigated case study were ascribed to the use of different surface heat transfer coefficients and to a different modeling of the extra thermal radiation to the sky. Degerfeld et al. [12] carried out a sensitivity analysis to highlight the strengths and the weakness of the new approach considered a multi-unit residential building as case study. Mazzarella et al. [13], instead, compared the method of EN 52016-1 with the alternative one understudied in the national Annex A of standard for the definition of number of nodes and position.

The present work aims at comparing the new approach (EN 52016) with the current calculation method (UNI 11300) in the national EPBD calculation framework. Three building models comply with nZEB requirements were chosen as case studies, and the paper is structured as follows: section 2 describes the chosen case studies and a briefly description of the two procedures. Results related to energy simulation with 11300 and 52016 are discussed in section 3, whilst the main conclusions are exposed in section 4 .

\section{Material and Methods}

UNI EN ISO 52016 [7] has been replaced the UNI EN ISO 13790 [5], on which the $\mathrm{UNI} / \mathrm{TS} 11300[3,4]$ were based on, and it represents the new standard for the energy performance calculation of buildings.

The new standard introduces the dynamic hourly method for calculating energy requirements for heating and cooling, which will flank the current quasi-steady method defined by the previous regulation [5].

The quasi-steady method is a simplified monthly calculation method and it can be considered "steady" because the elementary calculation interval is totally independent from the other ones, i.e. what happens in the one interval does not affect the next one. The dynamic effects are taken into account with two utilization factors.

On the other hand, the new hourly dynamic method allows assessing the energy performance of a building by taking into account the inertial effects of the building envelope (and systems) and considering the hourly time variation of instantaneous changes in external 
environmental and microclimatic parameters and of internal systems (temperature, relative humidity, system response, etc.). This method can be considered as "dynamic" because the calculation in one elementary interval takes into account the results of the previous interval.

In this section after a briefly description of the two calculation methodologies, the characterization of the three case studies are described.

\subsection{UNI EN ISO 13790 - UNI TS 11300}

The proposed calculation method by EN ISO 13790 [5] and UNI 11300 [3, 4] is based on monthly average energy calculation starting from monthly mean values of air temperature and solar radiation. According to [3, 4], the primary energy required for heating and cooling of buildings is calculated from energy need, based on thermal properties of building envelope, and from the energy efficiency of technical building systems.

This methodological approach is also the current calculation method adopted for the Energy Performance Certifications (EPCs) by using standard input data about outdoor conditions and operating schedules of building.

In the monthly method, the energy need of the buildings for heating $\left(\mathrm{Q}_{\mathrm{H}, \mathrm{nd}}\right)$ and cooling $\left(\mathrm{Q}_{\mathrm{C}, \mathrm{nd}}\right)$ are assessed by means energy balance of the heat losses through the building envelope $\left(\mathrm{Q}_{\mathrm{H}, \mathrm{ht}}\right.$ and $\left.\mathrm{Q}_{\mathrm{C}, \mathrm{ht}}\right)$ and the total heat gains $\left(\mathrm{Q}_{\mathrm{gn}}\right)$ including solar and internal heat gains. In the heating balance, $Q_{g n}$ value is corrected by an utilization factor $\left(\eta_{\mathrm{H}, \mathrm{gn}}\right)$, on the other hand in the cooling energy balance a similar utilization factor $\left(\eta_{\mathrm{C}, \mathrm{ls}}\right)$ is used for the correction of $\mathrm{Q}_{\mathrm{C}, \mathrm{ht}}$. Therefore, these utilization factors represent the gains (heating) or the losses (cooling) that reduce the heating or cooling energy need.

$$
\begin{aligned}
& Q_{H, n d}=Q_{H, h t}-\eta_{H, g n} \cdot Q_{g n} \\
& Q_{C, n d}=Q_{g n}-\eta_{C, l s} \cdot Q_{C, h t}
\end{aligned}
$$

The utilization factors can be evaluated as follow:

$$
\begin{gathered}
\eta_{H, g n}=\frac{1-\gamma_{H}^{a_{H}}}{1+\gamma_{H}^{a_{H}+1}} \\
\eta_{C, l s}=\frac{1-\gamma_{C}^{-a_{C}}}{1+\gamma_{C}^{-\left(a_{C}+1\right)}}
\end{gathered}
$$

Where $\gamma_{\mathrm{H}}$ and $\gamma_{\mathrm{C}}$ are calculated as the ratio of heat gains and losses for heating and cooling respectively, while $\mathrm{a}_{\mathrm{H}}$ and $\mathrm{a}_{\mathrm{C}}$ are linearly correlated with the constant time of the building and other two parameters for which default values are provided [3].

Moreover, the values of $\eta_{\mathrm{H}}$ and $\eta_{\mathrm{C}}$ are much influenced data because they can also affected the heating and cooling period calculation of each building when non-standard evaluation are performed; in standard calculation, such as in EPCs, conventional heating period are assumed.

\subsection{UNI EN ISO 52016}

The EN ISO 52016-1 [7] provides a calculation procedure to assess the energy need of conditioned space, at hourly and monthly scale, based on an RC network thermal model (Fig. 1), for each building component. 
The aim of method is to improve the accuracy of the energy evaluations, taking into account the influence of hourly variations of climate conditions, operation parameters (solar shading, occupation, ecc) thermal accumulation in the building structures, etc. and their dynamic interactions.

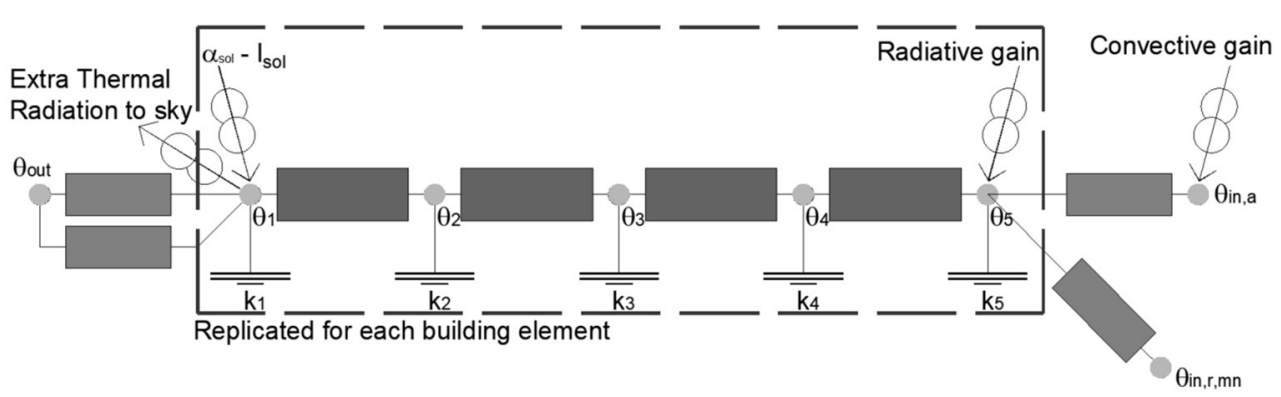

Fig. 1. RC network thermal model provided by UNI EN 52016 [7].

The implemented RC model, allows representing each element as composed of 5 nodes with 4 thermal resistances and different number of thermal capacities depending on the position of mass but not directly linked to the stratigraphy of the structure considered.

The balance equations of energy, air-mass and water vapour, for each building thermal zone are carried out at hourly basis and allows calculating the energy need. In Table 1 the main data outputs are reported for sensible load.

Table 1. Main outputs of UNI EN 52016 [7].

\begin{tabular}{|c|c|c|}
\hline Output & Symbol & Unit \\
\hline Sensible energy need for heating and cooling & $\mathrm{Q}_{\mathrm{H}, \mathrm{nd}}-\mathrm{Q}_{\mathrm{C}, \mathrm{nd}}$ & $\mathrm{kWh}$ \\
\hline Internal operative temperature, & $\theta_{\text {int,op }}$ & ${ }^{\circ} \mathrm{C}$ \\
\hline Sensible hourly heating and cooling load & $\Phi_{\mathrm{H}, \mathrm{ld}}-\Phi_{\mathrm{C}, \mathrm{ld}}$ & $\mathrm{W}$ \\
\hline Internal operative temperature & $\theta_{\text {int,op }}$ & ${ }^{\circ} \mathrm{C}$ \\
\hline Internal mean radiant temperature & $\theta_{\text {int,r,mn }}$ & ${ }^{\circ} \mathrm{C}$ \\
\hline Indoor air temperature & $\Theta_{\text {int,a }}$ & ${ }^{\circ} \mathrm{C}$ \\
\hline
\end{tabular}

Corresponding data outputs are provided for latent energy loads and for humidification and dehumidification energy needs $(\mathrm{kWh})$ and for internal moisture content $(\mathrm{kg} / \mathrm{s})$. The main assumptions, as reported in the calculation procedure of the standard ISO 52016 [7] are summarized below:

- the air temperature of thermal zone is considered uniform;

- the heat conduction through the room or zone elements is assumed to be onedimensional;

- the solar radiation distribution in the space considered is assumed uniform and timeindependent;

- thermal bridges are calculated in stationary conditions without consider the heat storage contribution;

- the heat storage effects of a glazed surfaces are neglected;

- solar properties of windows are not solar angle dependent;

- the total solar energy transmittance is assumed to be direct transmittance into the zone. 
In accordance with EPB standards, the definition of specific annex is ongoing at national level to introduce adjustments in the calculation procedure [13], but in this study simplified hourly method as transposed in Italian national standard UNI 52016:2018 has been applied to evaluate di energy performance of nZEB reference buildings in standard conditions (Asset rating).

\subsection{Case studies}

In the present paper, three different case studies are investigated by applying both described procedures. The selected models are all "reference buildings" defined by the decrees of 26 June 2015 [2] with the thermal properties supplied by the law since 01/01/2021 (minimum requirements for the nZEB building envelope) according to the climatic zone.

The energy simulations were performed in all the climatic zone of Italian territory; in particular, one location for each climatic zone was chosen basing on Heating Degree Days (HDD):

- Location 1: Lampedusa in zone $\mathrm{A}(\mathrm{HDD} \leq 600)$;

- Location 2: Siracusa in zone B $(600<\mathrm{HDD} \leq 900)$;

- Location 3: Salerno in zone C $(900<\mathrm{HDD} \leq 1.400)$;

- Location 4: Firenze in zone D $(1.400<\mathrm{HDD} \leq 2.100)$;

- Location 5: L'Aquila in zone E $(2.100<\mathrm{HDD} \leq 3.000)$;

- Location 6: Belluno in zone F (HDD > 3.000).

The three models were defined by considering the main typologies, form, and building construction of the Italian building stock:

- $\quad$ Case study 1: residential building (detached house);

- Case study 2: residential building (multi-family building);

- $\quad$ Case study 3: non-residential building (office).

The main geometrical characteristics of the three case studies are shown in Table 2 whilst the main thermal properties in compliance with national regulation [2] are shown in Table 3 for each climatic zone.

Table 2. Geometric characteristics of the three chosen case studies.

\begin{tabular}{|c|c|c|c|c|}
\hline Geometric characteristics & unit & $\begin{array}{c}\text { Detached } \\
\text { house }\end{array}$ & $\begin{array}{c}\text { Multi-family } \\
\text { building }\end{array}$ & Office \\
\hline Number of floor & & 1 & 6 & 4 \\
\hline Ground floor net area & $\mathrm{m}^{2}$ & 93 & 236 & 398 \\
\hline Conditioned net area $\left(\mathrm{A}_{\mathrm{f}, \mathrm{n}}\right)$ & $\mathrm{m}^{2}$ & 93 & 1416 & 1591 \\
\hline Total Windows area $\left(\mathrm{A}_{\mathrm{win}}\right)$ & $\mathrm{m}^{2}$ & 12 & 181 & 424 \\
\hline Conditioned net Volume $\left(\mathrm{V}_{\mathrm{n}}\right)$ & $\mathrm{m}^{3}$ & 251 & 3825 & 4296 \\
\hline Conditioned gross Volume $\left(\mathrm{V}_{\mathrm{g}}\right)$ & $\mathrm{m}^{3}$ & 421 & 5137 & 5644 \\
\hline External Heat transfer surface $\left(\mathrm{A}_{\text {envelope }}\right)$ & $\mathrm{m}^{2}$ & 390 & 2222 & 2437 \\
\hline Shape factor $\left(\mathrm{A}_{\text {envelope }} / \mathrm{V}_{\mathrm{g}}\right)$ & $\mathrm{m}^{-1}$ & 0,92 & 0.43 & 0.43 \\
\hline Glazing surface ratio $\left(\mathrm{A}_{\text {win }} / \mathrm{A}_{\text {envelope }}\right)$ & $\%$ & 3 & 8 & 17 \\
\hline
\end{tabular}


Table 3. Minimum thermal transmittance $\left[\mathrm{W} / \mathrm{m}^{2} \mathrm{~K}\right]$ of reference buildings provided by Italian regulation [2] for each chosen city.

\begin{tabular}{|c|c|c|c|c|c|c|}
\hline Component & Lampedusa & Siracusa & Salerno & Firenze & L'Aquila & Belluno \\
\hline External vertical walls & 0,43 & 0,43 & 0,34 & 0,29 & 0,26 & 0,24 \\
\hline Ground floor & 0,44 & 0,44 & 0,38 & 0,29 & 0,26 & 0,24 \\
\hline Roof & 0,35 & 0,35 & 0,33 & 0,26 & 0,22 & 0,20 \\
\hline Windows & 3,00 & 3,00 & 2,20 & 1,80 & 1,40 & 1,10 \\
\hline
\end{tabular}

Moreover, in order to compare to each other the two calculation methodologies, the following assumptions were also done:

- $\quad$ The energy need for heating was evaluated by considering the heating period supplied by national regulation [2,3] depending on Heating Degree Days;

- The energy need for cooling was evaluated considering complementary period to heating for UNI 52016 and in accordance with UNI TS 11300;

- The same internal heat gains (due to the people, machine and so on) are assumed in both the procedures;

- $\quad$ The climate data are provided by UNI 10349 [14];

- $\quad$ No shading systems have been considered;

- The air change rate (ventilation rate) have been set according to UNI TS 11300 equal to $0.5 \mathrm{vol} / \mathrm{h}$ for residential buildings and $1,05 \mathrm{vol} / \mathrm{h}$ for the office in both the procedures.

The comparison of the two calculation procedures was also carried out by setting $20^{\circ} \mathrm{C}$ and $26^{\circ} \mathrm{C}$ as set-point values during the heating and cooling periods. Moreover, the analysis does not take into account the influence of energy system, which is not yet considered in the current implementation of standard EN ISO 52016-1.

\section{Results and discussion}

Once defined the three case studies and their boundary conditions, energy simulations were carried out in compliance with UNI 11300 [3, 4] and EN 52016 [7].

Below, the energy needs per net surface $\left[\mathrm{kWh} / \mathrm{m}^{2}\right]$ for heating and for cooling of the two residential case studies are reported and discussed at first. Results of the detached house are shown in Fig. 2 (heating) and in Fig. 3 (cooling) whilst the ones related to multi-family building are shown in Fig. 4 (heating) and in Fig. 5 (cooling).

According to the figures, it is possible to state the following:

1. Detached house: the difference between the two calculation methods is about of $10-40 \%$ for the energy need for heating and up to $50-90 \%$ for the energy need for cooling. In both cases, the higher values of energy needs were found with UNI 11300;

2. Multi-family building: although the absolute difference between the two methods is lower than detached house, the relative difference increase up to $60 \%$ for the heating and it is in $70-85 \%$ for the cooling. Also in this case, the higher values of energy needs were found with UNI 11300.

According to the results, it is important to point out for the residential case studies the following:

1. The intermediate floor units of multi-family building require a lower energy needs for heating (due to the smaller heat exchange surface) than the units at the 
top and ground floor, involving a lower specific energy need for heating with respect to the detached house. Mean values of $9.8 \mathrm{kWh} / \mathrm{m}^{2}$ and $7.7 \mathrm{kWh} / \mathrm{m}^{2}$ for the multi-family building with the UNI TS 11300 and EN 52016 respectively, whilst $35.2 \mathrm{kWh} / \mathrm{m}^{2}$ (UNI TS 11300) and $26.6 \mathrm{kWh} / \mathrm{m}^{2}$ (EN 52016) for the detached house were found.

On the other hand, different trend can be noticed during the summer time by applying the EN 52016 or UNI TS 11300 approach. With the current regulation (UNI TS 11300) the multi-family building has a higher specific energy consumption (mean value of $29.1 \mathrm{kWh} / \mathrm{m}^{2}$ vs $21.1 \mathrm{kWh} / \mathrm{m}^{2}$ of the detached house), but with the new regulation (EN 52016) an opposite trend was found (mean value of $6.3 \mathrm{kWh} / \mathrm{m}^{2}$ vs $9.6 \mathrm{kWh} / \mathrm{m}^{2}$ of the detached house). This result can be due to the different approaches adopted for the energy balance;

2. The differences found for the energy need for heating of the two residential case studies seem to basically decrease with the severity of the climatic conditions, i.e. with the increasing of Heating Degree Days, whilst no kind of correlation was highlighted during the cooling period.

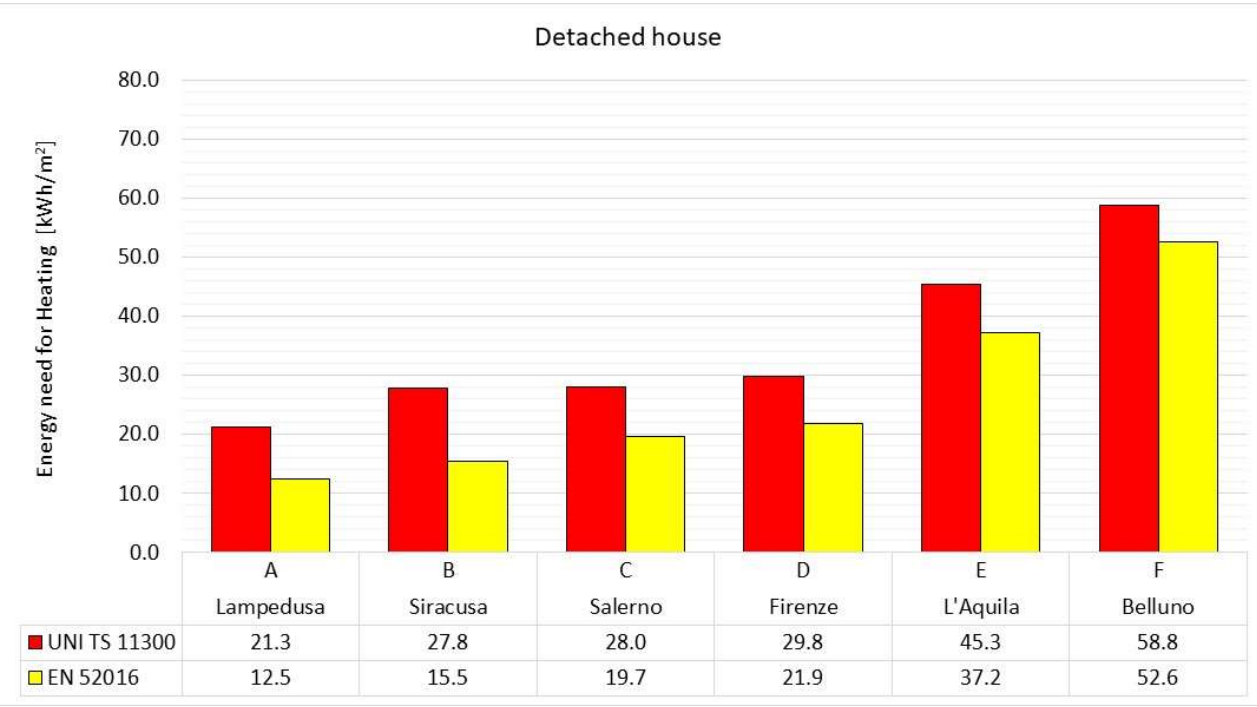

Fig. 2. Energy need for heating of the detached house: UNI 11300 vs EN 52016. 


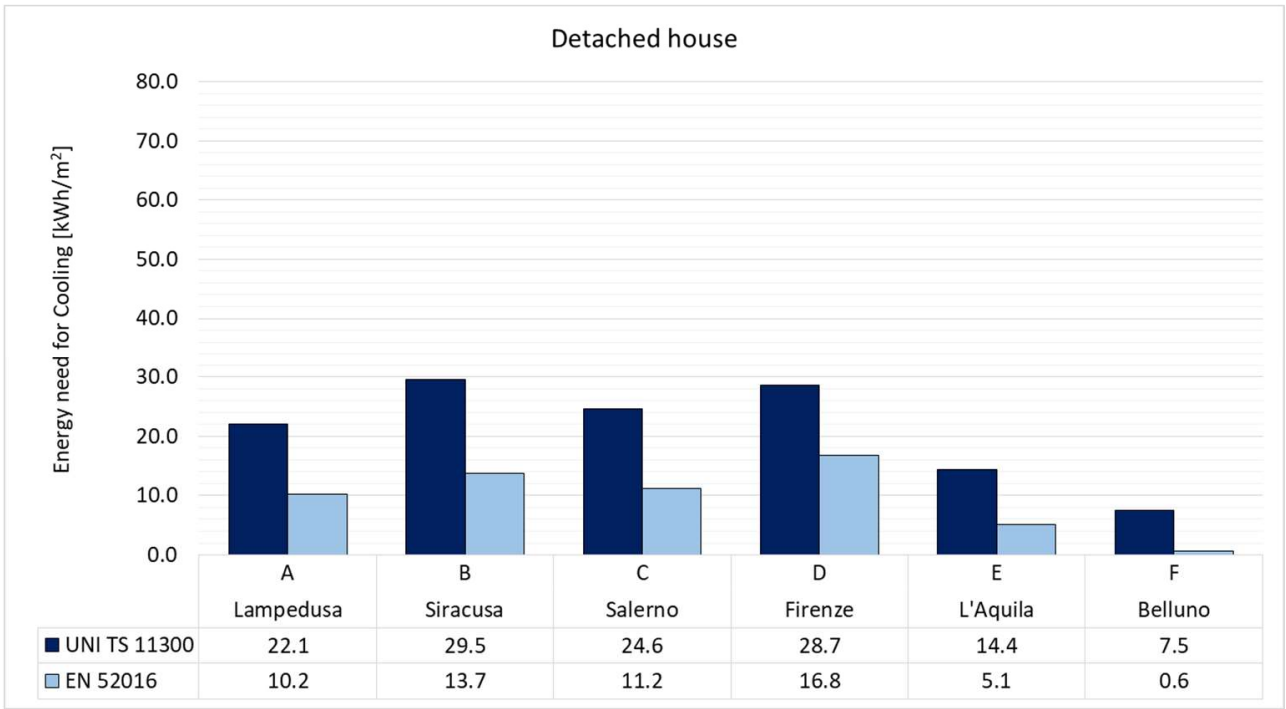

Fig. 3. Energy need for cooling of the detached house: UNI 11300 vs EN 52016.

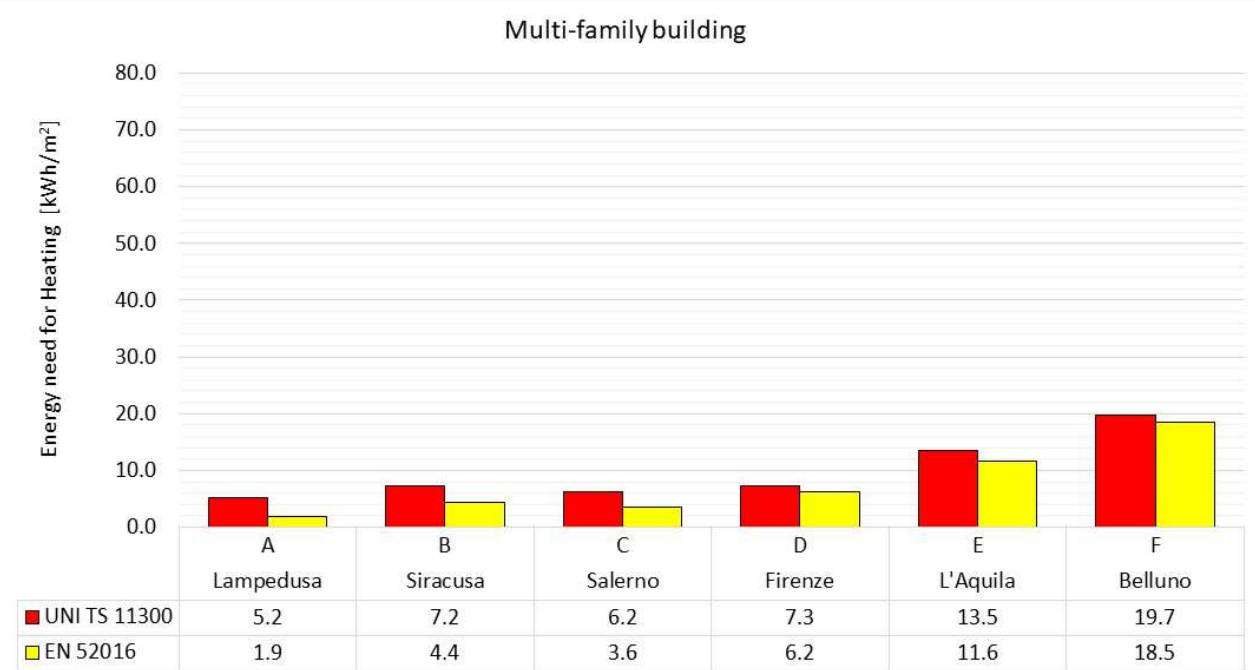

Fig. 4. Energy need for heating of the multi-family building: UNI 11300 vs EN 52016. 


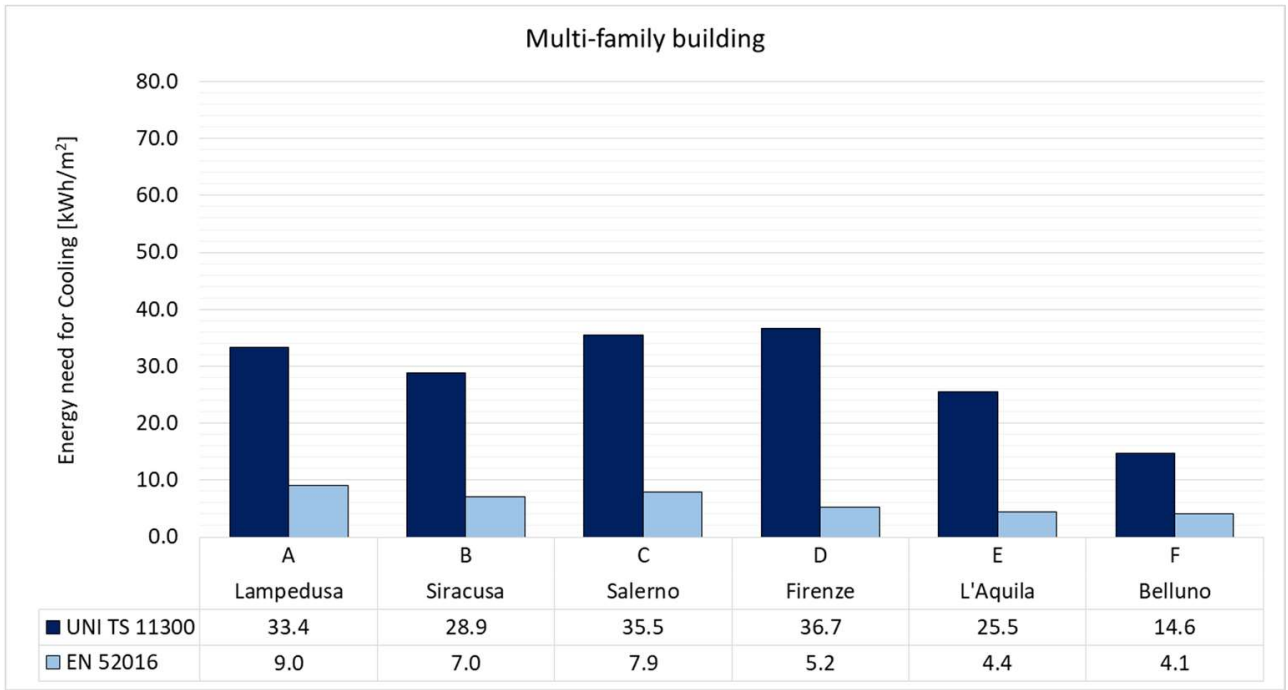

Fig. 5. Energy need for cooling of the multi-family building: UNI 11300 vs EN 52016.

The third case was the office which differs from the previous models especially for the large glazed surfaces and the air exchange rate.

In this case, the heating energy needs obtained by applying the UNI TS 11300 was higher than the UNI 52016 in all the considered zones, with differences ranging from 5\% (L'Aquila) to $23 \%$ (Siracusa).

Moving to the cooling energy needs, the same trend but with more relevant differnces was found: in this case the values obtained by UNI TS 11300 were much higher, ranging between 23\% (Firenze) and 41\% (L'Aquila and Lampedusa).

It is interesting to note that, as seen for residential buildings, no evident climatic dependancy is highlighted: it can be due to the chosen sites (selected as a function of Heating Degree Day) but also to the more complexity of heat exchange in summer season.

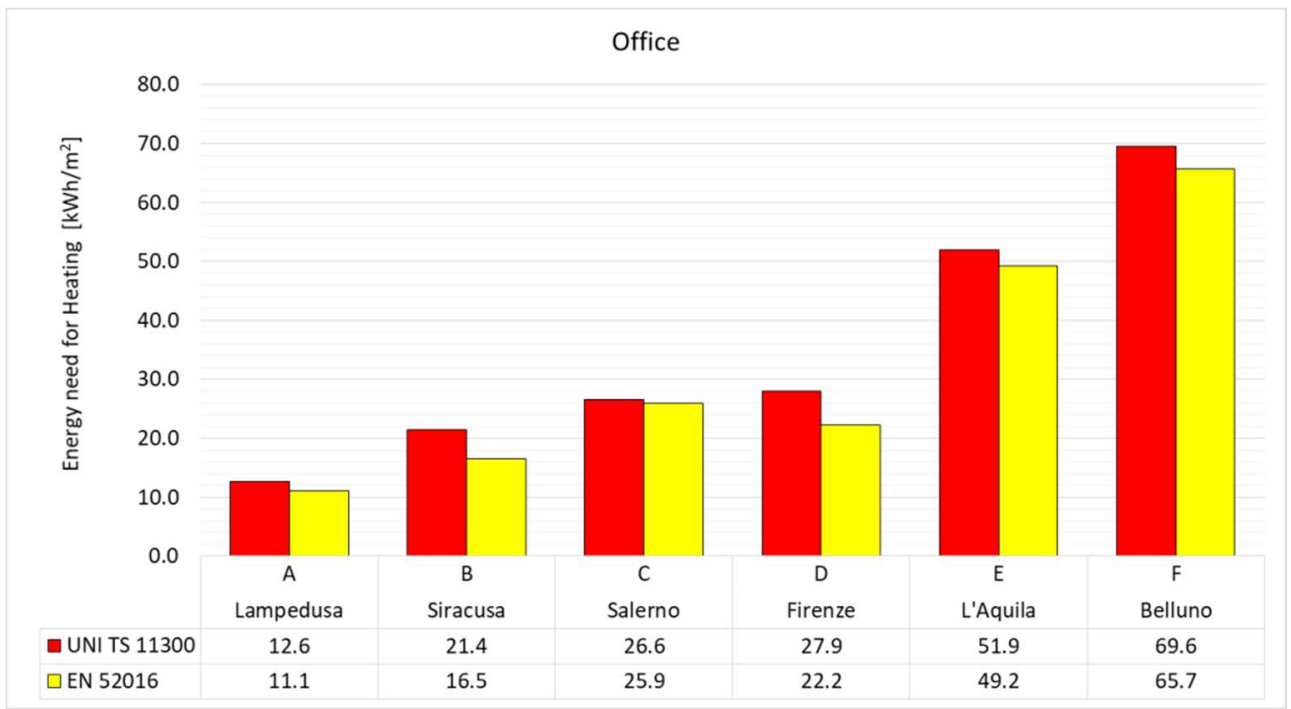

Fig. 6. Energy need for heating of the Office: UNI 11300 vs EN 52016. 


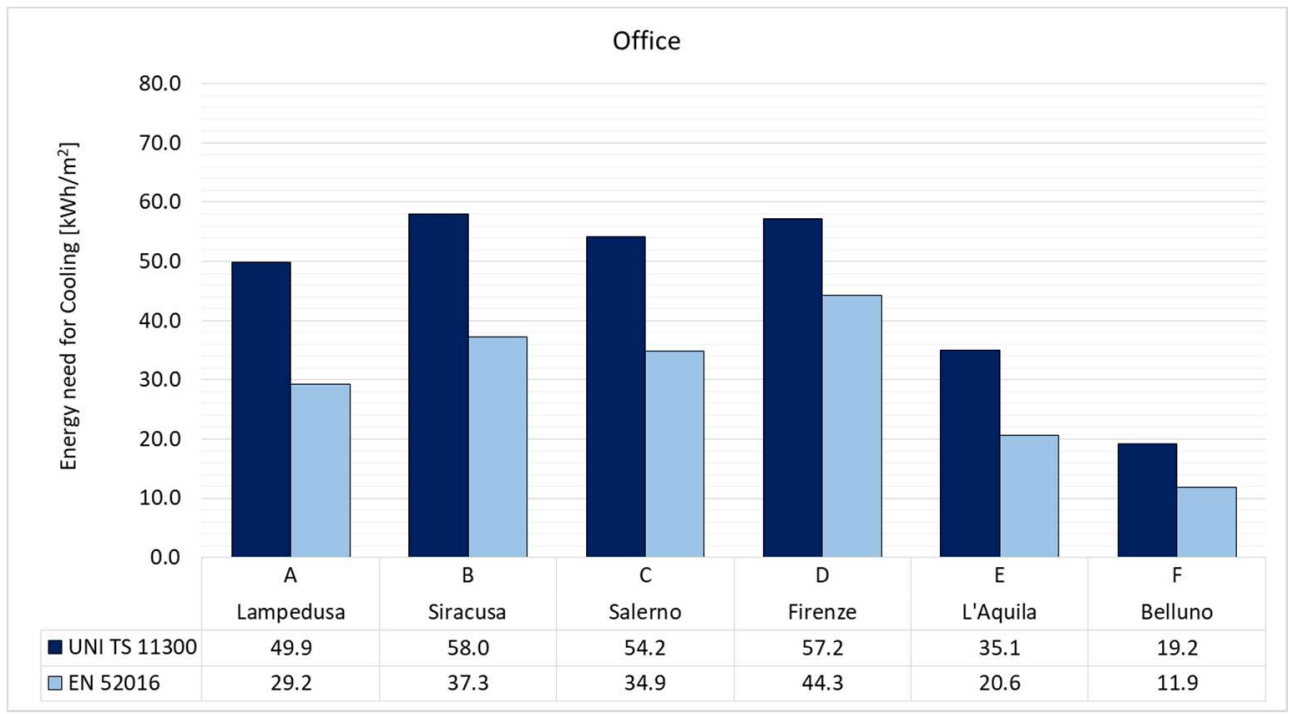

Fig. 7. Energy need for heating of the Office: UNI 11300 vs EN 52016.

The energy needs obtained by applying the two approaches were compared more in details by analysing the percentage differences of the two main components of energy balance:

1. Transmission and ventilation;

2. Solar and internal heat gains.

Results are summarized in Table $\mathbf{4}$ and Table 5 for the heating and cooling energy needs respectively. From these tables, it is possible to highlight significant differences related to the type of buildings and to the climatic zones, but no specific and common trend was found. However, the mean difference between the two approaches is lower in the heating period, mainly ranging in $\pm 20 \%$ range for transmission and ventilation component and in $\pm 40 \%$ range for the heat gains. Differences that are much more relevant can be noticed for the cooling energy balance with large percentage variations ranging, especially for the multifamily building.

These findings seem to confirm a fair convergence in the winter calculations and the more complexity of summer energy need calculation in which the cooling load, mainly linked to the solar radiation and internal heat gains, can vary greatly during the hours of the day.

In this perspective, the hourly dynamic method seems to be more appropriate method, but more deep analysis are needed to investigate the evaluation of cooling energy needs for different type of building envelopes and for different conditions and operation schedules of technical building systems. 
Table 4. Heat transfer differences in energy balance for each case study: heating.

\begin{tabular}{|c|c|c|c|c|c|c|}
\hline \multirow{2}{*}{$\begin{array}{c}\text { Climate } \\
\text { zone }\end{array}$} & \multicolumn{2}{|c|}{ Transmission and Ventilation } & \multicolumn{3}{c|}{ Solar and Internal gain } \\
\cline { 2 - 7 } & $\begin{array}{c}\text { Detached } \\
\text { house }\end{array}$ & $\begin{array}{c}\text { Multi-family } \\
\text { building }\end{array}$ & Office & $\begin{array}{c}\text { Detached } \\
\text { house }\end{array}$ & $\begin{array}{c}\text { Multi-family } \\
\text { building }\end{array}$ & Office \\
\hline A & $7 \%$ & $-3 \%$ & $-10 \%$ & $-26 \%$ & $7 \%$ & $-1 \%$ \\
\hline B & $9 \%$ & $-6 \%$ & $-11 \%$ & $-35 \%$ & $6 \%$ & $-2 \%$ \\
\hline C & $9 \%$ & $-19 \%$ & $-10 \%$ & $-15 \%$ & $0 \%$ & $-5 \%$ \\
\hline D & $0 \%$ & $15 \%$ & $-14 \%$ & $-18 \%$ & $39 \%$ & $-30 \%$ \\
\hline E & $3 \%$ & $10 \%$ & $-6 \%$ & $-16 \%$ & $24 \%$ & $-3 \%$ \\
\hline F & $0 \%$ & $12 \%$ & $-5 \%$ & $-17 \%$ & $29 \%$ & $-6 \%$ \\
\hline
\end{tabular}

Table 5. Heat transfer differences in energy balance for each case study: cooling.

\begin{tabular}{|c|c|c|c|c|c|c|}
\hline \multirow{2}{*}{$\begin{array}{c}\text { Climate } \\
\text { zone }\end{array}$} & \multicolumn{2}{|c|}{ Transmission and Ventilation } & \multicolumn{3}{c|}{ Solar and Internal gain } \\
\cline { 2 - 7 } & $\begin{array}{c}\text { Detached } \\
\text { house }\end{array}$ & $\begin{array}{c}\text { Multi-family } \\
\text { building }\end{array}$ & Office & $\begin{array}{c}\text { Detached } \\
\text { house }\end{array}$ & $\begin{array}{c}\text { Multi-family } \\
\text { building }\end{array}$ & Office \\
\hline A & $46 \%$ & $-62 \%$ & $71 \%$ & $33 \%$ & $2 \%$ & $52 \%$ \\
\hline B & $16 \%$ & $-112 \%$ & $68 \%$ & $15 \%$ & $5 \%$ & $47 \%$ \\
\hline C & $63 \%$ & $-13 \%$ & $80 \%$ & $45 \%$ & $4 \%$ & $54 \%$ \\
\hline D & $10 \%$ & $-34 \%$ & $74 \%$ & $16 \%$ & $2 \%$ & $39 \%$ \\
\hline E & $62 \%$ & $-22 \%$ & $80 \%$ & $53 \%$ & $-9 \%$ & $57 \%$ \\
\hline F & $71 \%$ & $-104 \%$ & $80 \%$ & $65 \%$ & $-73 \%$ & $60 \%$ \\
\hline
\end{tabular}

\section{Conclusions}

The present paper aims to investigate the differences of the monthly quasi steady-state (UNI TS 11300) and the hourly dynamic (EN 52016) calculation procedures on energy assessment of new buildings according to Italian nZEB targets. Since at this moment the main differences of the two procedures lie on the resistance-capacity (RC) model implemented in EN ISO 52016 for calculation of building envelope heat exchange, the analyses has been focused on the net energy need for heating and cooling, without taking into account the efficiency of energy systems.

Numerical simulations on three reference building models were carried out in different climatic zones, in order to compare the two different approaches in accordance with national regulations for asset rating calculation framework.

Results highlighted important differences between the two approaches: the energy needs for heating returned by hourly dynamic calculation procedure is quite close but lower of about $10-40 \%$ than monthly quasi steady-state outputs. On the other hand, higher percentage of $40-$ $90 \%$ were found for the energy need for cooling for all reference case considered.

This preliminary study has allowed pointing out significant differences of energy need mainly due to different weight of heat loss and heat gains in each energy balance. Moreover, further relevant aspect is that the use of hourly climatic data set for numerical simulation as required by ISO 52016 dynamic method, can significantly affect the energy performance assessments of buildings in the next years.

However, further analysis are needed in order to better evaluate the impact of new calculation method on the energy assessment of different kind of buildings and to take in account the influence of the energy systems in different operating conditions. 


\section{References}

1. Directive 2010/31/EU of the European Parliament and of the Council of 19 May 2010 on the energy performance of buildings. Off. J. Eur. Union. (2010).

2. Inter-ministerial Decree of 26rd June 2015. Application of methodologies for the energy calculation and definition of prescriptions and minimum requirements for buildings (2015) (in Italian)

3. UNI TS 11300 - Part 1, Energy Performance of Buildings - Evaluation of energy need for space heating and cooling (2014) (in Italian)

4. UNI TS 11300 - Part 2, Energy Performance of Buildings - Evaluation of primary energy need and of system efficiencies for space heating, domestic hot water production, ventilation and lighting for non-residential buildings (2019) (in Italian)

5. UNI EN ISO 13790. Energy performance of buildings - Calculation of energy use for space heating and cooling (2008)

6. Directive (EU) 2018/844 of the European Parliament and of the Council, of 30 May 2018 amending Directive 2010/31/EU on the energy performance of buildings and Directive 2012/27/EU on energy efficiency (2018)

7. UNI EN ISO 52016-1. Energy performance of buildings - Energy needs for heating and cooling, internal temperatures and sensible and latent heat loads - Part 1: Calculation procedures (2018)

8. G. Barone, A. Buonomano, C. Forzano, G.F. Giuzio, A. Palombo. Bibliografic research on the methodologies for the assessment of heating and cooling energy need of buildings, 036 (2019) (in Italian)

9. T. Zakula, M. Bagaric, N. Ferdelji, B. Milovanovic, S. Mudrinic, K. Ritosa, Applied Energy 254, 113553 (2019)

10. I. Ballarini, E. Primo, V. Corrado, Thermal Science 22, 1117-1127 (2018)

11. I. Ballarini, A. Costantino, E. Fabrizio, V. Corrado, Energies 13, 6217 (2020)

12. F.B.M. Degerfeld, I. Ballarini, G. DeLuca, M.P. Tootkaboni, V. Corrado, E3S Web Conf. 197, 02012 (2020)

13. L. Mazzarella, R. Scoccia, P. Colombo, M. Motta, Energy and Buildings 210, 109758 (2020)

14. UNI 10349, Heating and Cooling of Buildings. Mean monthly data for the thermalenergy performance evaluation of buildings and methods for calculating direct and diffused solar irradiances and the solar irradiance on sloping surface (2016) 